\title{
Nano-sized Tin Oxide-Modified Graphite Composite as Efficient Anode Material for Lithium Ion Batteries
}

\author{
Chia-Chin Chang ${ }^{1,4, *}$, Li-Chia Chen ${ }^{1}$, Tai-Ying Hung ${ }^{2}$, Yuh-Fan Su ${ }^{1}$, Huang-Kai Su ${ }^{1}$, \\ Jarrn-Horng Lin ${ }^{2}$, Chih-Wei Hü, Lakshmanan Saravanan ${ }^{4}$, Tsan-Yao Chen ${ }^{3}$ \\ ${ }^{1}$ Department of Greenergy, National University of Tainan, Tainan 70005, Taiwan \\ ${ }^{2}$ Department of Material Science, National University of Tainan, Tainan 70005, Taiwan \\ ${ }^{3}$ Department of Engineering and System Science, National Tsing Hua University, Hsinchu 30013, \\ Taiwan \\ ${ }^{4} \mathrm{R} \&$ D Center for Li-ion Battery, National University of Tainan, Tainan 70005, Taiwan \\ *E-mail: ccchang@mail.nutn.edu.tw
}

doi: $10.20964 / 2018.12 .28$

Received: 17 July 2018 / Accepted: 9 September 2018 / Published: 5 November 2018

\begin{abstract}
Nano-sized tin based compounds dispersed graphite composites, synthesized by the electroless plating process and pyrolysis method, act as efficient anode materials for lithium ion batteries (LIBs). The nano-sized tin complexes on the graphite surface can be obtained through a simple chemical reaction between $\mathrm{Sn}(\mathrm{BF} 4)_{2}$ and $\mathrm{Na}_{2} \mathrm{~S}_{2} \mathrm{O}_{4}$ in aqueous solution and completely converted to $\mathrm{SnO}_{2}$ after pyrolysis. The synthesized tin-modified graphite composites were characterized by X-ray diffraction (XRD), field-emission scanning electron microscopy (FE-SEM), and high-resolution transmission electron microscopy (HRTEM). The electrochemical performance of the composites for application as anode materials in lithium-ion batteries was investigated. The average particle size of nano- $\mathrm{SnO}_{2}$ is $\sim 14.7 \mathrm{~nm}$, as determined by HRTEM. Results of infrared spectra and electrochemical properties indicate that such an optimized nano Sn-based compound on graphite influences the formation of the thin solid electrolyte interface (SEI) in the electrode and thus improves the cycling performance, with high efficiency of $97.3 \%$ in LIBs. Nyquist plots show that during $\mathrm{Li}^{+}$intercalation, the thin SEI film and the low charge transfer resistance of $\mathrm{SnO}_{2}$-modified graphite composite anode plays important roles in improving the electrochemical properties of LIBs.
\end{abstract}

Keywords: Graphite; $\mathrm{SnO}_{2}$; Anode; Electroless method; Lithium ion battery

\section{FULL TEXT}

(C) 2018 The Authors. Published by ESG (www.electrochemsci.org). This article is an open access article distributed under the terms and conditions of the Creative Commons Attribution license (http://creativecommons.org/licenses/by/4.0/). 